\title{
Geopolítica dos recursos naturais estratégicos e questão agrária em Moçambique: a Vale S.A. e o extrativismo epidêmico
}

\section{Geopolitics of strategic natural resources and agrarian question in Mozambique: the multinacional Vale S.A. and the epidemic extractivism}

\author{
Guilherme Magon Whitacker ${ }^{1}$ \\ Pós-Doutorando. Universidade Estadual Paulista Júlio de Mesquita Filho \\ Instituto de Políticas Públicas e Relações Internacionais \\ Programa de Pós-Graduação em Desenvolvimento Territorial na América Latina e Caribe \\ gwhitacker@gmail.com
}

\begin{abstract}
Resumo
Moçambique possui algumas das maiores reservas de recursos naturais de potencial energético do mundo, sobretudo, carvão mineral, gás natural e, mais recentemente descoberto, petróleo, ainda que em menor quantidade. Os recursos naturais energéticos são, ou podem ser, instrumentos de poder ou armas políticas. Destarte, determinam e condicionam ações sobre o uso dos territórios. Território e poder determinam relações instáveis e motivam pretextos para o surgimento de práticas e estratégias geopolíticas e todo recurso é produto de uma relação de poder sobre determinado território. Assim, os recursos naturais energéticos são considerados estratégicos, produtos das relações sociais de produção e do poder que interfere diretamente na posse dos mesmos e controle territorial, o que envolve, também, a conflitualidade gerada a partir da intensificação da questão agrária resultante desses processos.
\end{abstract}

Palavras-chave: Geopolítica dos recursos naturais, questão agrária, território, poder, Moçambique

\begin{abstract}
Mozambique has some of the world's largest reserves of natural resources with potential for energy, mainly mineral coal, natural gas and, more recently, oil, although in a smaller amount. Natural energy resources are or may be, instruments of power or political weapons. Thus, they determine and condition actions on the use of territories. Territory and power determine unstable relationships and motivate pretexts for the emergence of geopolitical practices and strategies, and every resource is the product of a power relationship over a given territory. Thus, natural energy resources are considered strategic, products of social relations of production and power that directly interfere in their possession and territorial control, which also involves the conflict generated by the intensification of the agrarian issue resulting from these processes.
\end{abstract}

Keywords: Geopolitics of natural resources, agrarian question, territory, power, Mozambique

\section{INTRODUÇÃO}

Durante o final do Século XX e início do Século XXI o avanço de multinacionais mineradoras em países subdesenvolvidos foi determinado por ações políticas visando o controle de novos espaços de acumulação e reprodução de capitais. Em Moçambique políticas que favorecem o extrativismo foram induzidos por agências multilaterais de desenvolvimento, sobretudo aquelas que figuram nos quadros do Grupo Banco Mundial (Grupo BM), voltadas a incorporação de uma

\footnotetext{
${ }^{1}$ Bolsista FAPESP. Processo no $2017 / 08847-3$
} 
dinâmica industrial de alta tecnologia por meio da entrada de Investimentos Externos Diretos (IED) vinculados a megaprojetos extrativistas já a partir da década de 1990. Essa mudança fez com que multinacionais buscassem espaços para redistribuir os investimentos em capital produtivo e, nesse contexto, o governo moçambicano foi cooptado e definiu alterações institucionais e internacionais para se inserir no mercado internacional de matérias primas com potencial estratégico, como carvão mineral, gás natural e petróleo. Novos modelos de desenvolvimento e crescimento econômico foram forjados tendo como base o extrativismo epidêmico ${ }^{2}$ que, pela sua lógica escalar e territorialista, acelerou a criação e expansão da capacidade tecnológica de extração em grande volume e escala incluindo redes logísticas que causam impactos socioterritoriais local e regionalmente.

Dialeticamente, o aumento na competição internacional por matérias primas de potencial energético gerou uma significativa demanda por energia, tendo em vistas a necessidade de mobilidade espacial de capitais e a construção de fixos territoriais, na forma de minas extrativistas e portos de exportação, incluindo toda a logística de transporte de minérios gás, ou petróleo, para garantir a fluidez deste modo de produção. Recursos naturais energéticos são considerados, então, como estratégicos desde a ótica capitalista e são convertidos em commodities. Exemplificando as questões abordadas acima, organizamos o texto em três partes, além da introdução e considerações finais. Em um primeiro momento apresentamos a base teórica que consideramos fundamental para entender a questão agrária provocada por megaprojetos extrativistas, a geopolítica dos recursos naturais estratégicos, posteriormente relacionamos a mesma a questão agrária moçambicana e, por fim, apresentamos a materialidade dos fatos com o exemplo da Vale Moçambique - subsidiária da Vale S.A. - que, em Moatize, província do distrito de Tete, explora carvão mineral impactando diretamente famílias desde a mina de extração até o porto de exportação no distrito de Nacala-aVelha $^{3}$. Os procedimentos utilizados incluem pesquisa empírica em Moçambique ${ }^{4}$ e revisão bibliográfica. Com esse artigo objetivamos demonstrar, de maneira concisa, os impactos socioterritoriais negativos que a Vale S.A., além do território brasileiro, causa pela intensificação do extrativismo, tornando essa forma de relação entre a sociedade e a natureza, mediada pelo trabalho, como um vírus que se alastra, uma epidemia.

\footnotetext{
2 Sobre o extrativismo epidêmico, escrevemos anteriormente (WHITACKER, 2019) sobre a dificuldade de operacionalização do conceito de neoextrativismo na Geografia, a opção pelo termo epidêmico decorre da relação entre o conceito geográfico de escala e a opção pelo território como categoria analítica.

${ }^{3}$ Sendo essa uma pesquisa em andamento, não apresentamos aqui mapas detalhados da localização dos megaprojetos extrativistas e da dinâmica territorial provocada pelos mesmos em Moçambique, esse detalhamento será apresentado em trabalhos futuros.

${ }^{4}$ Estivemos em Moçambique durante os meses de agosto e setembro de 2018 realizando pesquisa empírica para nossa pesquisa de Pós-Doutorado (Processo FAPESP nº 2017/08847-3).
} 


\section{DA GEOPOLÍTICA CRÍTICA A GEOPOLÍTICA DOS RECURSOS NATURAIS: BREVE ESBOÇO}

Interpretamos a geopolítica dos recursos naturais a partir da renovação epistemológica da Geografia durante a década de 1970 sob a influência pioneira e fundamental de Yves Lacoste (1976, 1993) e Richard Peet (1977, 1987) e suas influentes revistas internacionais - Hérodote e Antípode que contribuíram para renovar os limites da convencional geopolítica. Em trabalhos independentes, ambos autores contribuíram de diferentes formas, Yves Lacoste, em 1976 publica A Geografia. Isso serve, em primeiro lugar, para fazer a guerra, obra de importante papel de denúncia e fomento da renovação, de subsídios para a crítica da geopolítica tradicional, traz á tona a evolução do pensamento crítico na Geografia e surge, principalmente na França, a geopolítica crítica; por sua vez, Richard Peet, em The development of radical geography in the United States, publicado originalmente em 1977, indica a necessidade de uma ciência não neutra e a postura de determinado pesquisador frente a realidade, a esses dois geógrafos, somam-se outros como, James Anderson e David Harvey; no Brasil, destacamos o trabalho de Josué de Castro - diga-se de passagem, citado por Yves Lacoste em Geografia do subdesenvolvimento, publicado originalmente em 1965 -, Carlos Delgado de Carvalho, Therezinha de Castro, Manoel Correia de Andrade, Milton Santos, Armem Mamigoniam, Berta Becker e tantos outros que permitiram a evolução da Geografia e, particularmente, da geopolítica crítica.

Ponderamos que uma das características fundamentais da geopolítica crítica é a consideração de que a reflexão espacial e territorial sobre as relações de poder não pode se limitar pelo reducionismo, como ocorria na geopolítica tradicional, de considerar somente às relações de poder existentes entre os Estados. Pois, nesse caso, seriam desconsiderados os inumeráveis fixos e fluxos econômicos que ocorrem entre Estados e empresas multinacionais extrativistas, por exemplo, e os decorrentes conflitos nacionais e internacionais resultantes desse processo. Em consequência, faz-se necessário considerar as práticas territoriais e representações dos movimentos socioterritoriais que resistem, de diversas maneiras, à geopolítica dos Estados. Desse modo, ainda que a geopolítica crítica enfatize a macro-escala de análise não abandona outras, para não cair num determinismo geográfico.

Um dos precursores da geopolítica crítica, Simon Dalby, escreveu sobre a importância dos estudos críticos na análise espacial da aplicação de políticas:

What is being argued for here is nothing less than a recognition of the importance of studying the political operation of forms of geographical understandings, recognising that geographs are specifications of political reality that have political effect. To construct critical political geographies is to argue that we must not limit our attention to a study of the geography of politics within pregiven, taken-for-granted, commonsense spaces, but investigate the politics of the geographical specification of politics. That is to practice critical geopolitics (DALBY, 1991, p. 274). 
John Agnew colaborou com o entendimento sobre a geopolítica crítica incorporando dimensões de análise tendo em vistas compreender a elaboração de políticas de escala global e como elas mudam de acordo com as condições históricas.

The study of the impact of geographical distributions and divisions on the conduct of world politics. In it original usage it referred to the impact on inter-state relations of the spatial disposition of continents and oceans and the distribution of natural and human resources. Today, however, the term also covers examination of all of the geographical assumptions, designations and understandings that enter into the making of world politics (as in critical geopolitics) and how these change in concert with material conditions (historical geopolitics) (AGNEW, 2004, p. 135).

Por suas origens e evolução epistemológica, a geopolítica crítica é uma linha de pesquisa intrinsicamente multifacetada que não se apoia em uma única base teórica, nem em uma metodologia universalmente compartilhada. Essa pluralidade de enfoques está exposta em The Ashgate Research Companion to Critical Geopolitics, (DODDS, KUUS, SHARP, 2016), onde os autores oferecem uma clara perspectiva sobre o estado da arte da geopolítica crítica.

Sustained critique of mainstream geopolitical reasoning emerged at the end of the Cold War to challenge the strategic doctrines of that era and their legitimizing intellectual apparatus. The end of superpower rivalry, which had been the containing territorial structure of (geo)political thought for over 40 years, further fuelled interest in the spatiality of power in geography and indeed throughout the social sciences. It was in the context of the rethinking of power that this critique gained pace and gradually acquired the label "critical geopolitics" (DODDS, KUUS, SHARP, 2016, p. 6, aspas no original).

No capítulo intitulado The Origins of Critical Geopolitics, que abre o livro, John Agnew, após realizar extensa revisão bibliográfica em busca das matrizes dessa área específica da geopolítica conclui que essa surge como a necessidade de rever as espacialidades e territorialidades das relações de poder e enfatiza a dimensão crítica da geopolítica:

\begin{abstract}
What then, broadly speaking, does the sub-field have to offer? The first is a conceptual matrix for a geographical analysis of world politics based in ideas about geographical representations and socio-economic resources. Another is an emphasis on the role of vision (even in the mind's eye) in how the world is structured and acted on by political agents of various sorts. A third would be how important the fusion between territory and identity that has been in modern nationalism and how its role in dividing up the world still remains at work. Finally, I would identify its stress on the elite-based statecraft that has long lain at the heart of geopolitical reasoning and its necessary denial of the multidimensional qualities of different places in pursuit of an overriding Weltpolitik. In this perspective, then, there will be a need for critical geopolitics of some sort as long as the established nostrums of how the world is spatialized and divided up for political purposes remain in effect. (AGNEW, 2016, p. 32).
\end{abstract}

Outro eminente colaborador dessa perspectiva é Geraróid Ó Tuathail, que escreveu sobre a definição conceitual de geopolítica crítica e sua aplicação: 
As a concept, critical geopolitics is regularly evoked and knowingly used yet rarely problematized. There is not yet an adequate theoretical discussion of the functioning of geopolitics as a sign within critical geopolitics. Nor has there been an explicit theoretical discussion of how critical geopolitics should function and how it needs to engage what we have already identified as the geopolitical gaze (TUATHAIL, 2005, p. 48).

Dessas concepções sobre a geopolítica crítica é que propomos a geopolítica dos recursos naturais como uma potencial linha de pesquisa que, devido a característica escalar e territorialista do modo de produção capitalista e sua tendência de transformar todo e qualquer tipo de recurso natural em mercadoria, pode ser aplicada ao estudo de formas de produção de commodities e comércio, lícito e ilícito, nacional e internacional, entre países exportadores e importadores, entendendo que esse processo apresenta impactos socioterritoriais negativos, mormente nos países exportadores, que resultam, por exemplo, em conflitos, conflitualidade e guerras por recursos naturais, a geopolítica dos recursos naturais voltada ao estudo de questões moçambicanas pode objetivar, por tanto, compreender os processos e relações de poder internacionais que influem sobre o controle territorial em torno do acesso a recursos naturais estratégicos, fatos esses que inferem, portanto, na própria produção do espaço moçambicano, daí sua eminência geopolítica.

Para Philippe Le Billon a geopolítica dos recursos naturais se fundamenta a partir de três fatores estratégicos: à economia política e à governança dos países dependentes de recursos; à escala e ao número de fatores econômicos, conflitos sobre o controle de recursos naturais e interesses empresariais e, o terceiro fator, diz respeito as receitas geradas a partir dos recursos naturais.

The geopolitics of natural resources has long been a strategic concern for both exporting and importing states. Western powersí concerns over ëresource warsí have been largely put at ease with the end of the Cold War and greater flexibility of international trade, even if their continued supply dependence, rising demand for raw materials, and recent armed confrontations and instability in key areas such as the Persian Gulf, continue to place this item on their geopolitical agenda. But this apparent progress has not resolved and may even have aggravated several other strategic issues about resources, this time mostly of concern to exporting countries. The first issue relates to the political economy and governance of resource-dependent countries, many of which face a similar pattern of growth collapse, corruption, and delegitimated state authority. Given the importance of natural resources in the economy or the economic potential of many developing countries, the issue of translating resource exploitation into political stability and economic development will remain central in the years to come, often for entire regions. The second issue relates to the scale and number of economic, environmental or socio-cultural conflicts related to resource exploitation that increasingly oppose local populations, business interests, the state, and global environmental and human rights networks. While most conflicts are either peacefully negotiated or limited to social protest movements and small-scale skirmishes, in other cases customs of violence and a radicalization of ideologies turned them into fullscale civil wars. Organized opposition to processes of globalization unaccountable to local interests and growing demand for raw materials could increase such adversarial politics and the need for more effective dialogue. The third, and often related strategic issue is that natural resource revenues have become the economic mainstay of most wars in the postCold War context. Accessible and internationally marketable resources such as diamonds and timber, not to mention drugs, have played a significant role in conflicts in at least 20 countries during the 1990s. This is not to argue that those wars are only financed or motivated by the control of resources, but that resources figure prominently in their 
agendas, at least economically. Given the concentration of wars in poor countries with few foreign-earning sources, resources are likely to remain the economic focus of most belligerents in years to come. Even if conflict resourcesí come under greater regulatory pressure, there is a likelihood that criminal networks and unscrupulous businesses will pursue trading, especially those already involved in arms trafficking (LE BILLION, 2005, p. 22).

Por sua vez, Bernice Lee, contribui com a concepção de que os recursos naturais no mundo estão sendo gerenciados por uma economia política de mercado de commodities.

\begin{abstract}
These variables present an unambiguous reality: the world's natural resources are now governed by a new political economy of commodities. New global trends are emerging in the production, trade and consumption of both raw materials and intermediate products. Meanwhile, governments and other stakeholders are working to secure their access to those resources. In doing so, they are creating new fault lines on top of existing weaknesses and environmental uncertainties. In a new report by Chatham House, Resources Futures, I and my colleagues Felix Preston, Jaakko Kooroshy, Rob Bailey, and Glada Lahn argue that resource politics, not environmental preservation or sound economics, are set to dominate the global agenda in the years ahead. Indeed, resource politics are already playing out, whether through trade disputes, climate negotiations, market manipulation strategies, aggressive industrial policies, or the scramble to control frontier áreas (LEE, 2013, p. 2).
\end{abstract}

Assim, compreendemos a geopolítica dos recursos naturais como uma distensão da Geografia e geopolítica crítica que permite o estudo sobre conflitos socioterritoriais em Moçambique que envolvem questões agrária relativas ao uso e controle de recursos naturais e permite que este processo seja estudado por distintas perspectivas, mas, tendo em comum o território como categoria analítica, pois este é o lócus da materialidade de conflitos e conflitualidades determinados por distintos usos dos territórios.

Uma primeira forma de estudo pode ser aquela dedicada aos constantes conflitos bélicos por recursos naturais (HENDRIX; NOLAND, 2004), (NEVINS, 2004), (KLARE, 2001, 2004, 2008, 2012), envolvendo petróleo e gás natural (OLAYLE, 2012), (LE BILLION, 2006), (OVERLAND, 2015), água (WELZER, 2010), (BARLOW; CLARCKE, 2003), (RIBEIRO, 2001, 2008), minérios (HAGLUND, 1999), (ANDERSON; ANDERSON, 2018). Outra forma de análise pode ser aquela que envolve conflitos não bélicos, mas que abrangem conflitualidades territoriais entre multinacionais e camponeses tendo como objetivo o controle territorial para produção e exportação de commodities "[...] A disputa territorial ocorre de dois modos: pela desterritorialização ou pelo controle das formas de uso e de acesso aos territórios, ou seja, controlando as suas territorialidades" (FERNANDES, 2009, p. 208), como os estudos realizados por (BAVINCK; PELLEGRINI; MOSTERT, 2014), (DICKEN, 2011), (MILANEZ, 2013), (PORTO-GONÇALVES, 2015), (GONÇALVES, 2016), (ZHOURI, 2016), (MORENO, 2017), e outros e, por nós, nesse breve esboço sobre o extrativismo epidêmico em Moçambique. 


\section{A GEOPOLÍTICA DOS RECURSOS NATURAIS ESTRATÉGICOS E A MOBILIDADE DE CAPITAIS}

Com o acirramento da fluidez das relações entre as unidades que constituem a totalidade do sistema econômico e político internacional, pelas constantes inovações que se verificam nos campos da informação, comunicação e transportes, os fluxos de capitais, mercadorias, serviços e pessoas tendem a não respeitar os limites fronteiriços. Num mundo cada vez mais interdependente, tais fatos implicam mudanças na organização espacial das atividades econômicas, sobretudo aquelas vinculadas ao fornecimento energético, pois, a energia é a responsável pelo processo que garante a fluidez de capitais, portanto, compreender as transformações que ocorrem no âmbito da economia política internacional, desde uma perspectiva geográfica que marca as relações internacionais, pode ser considerado como um dos objetivos da geopolítica dos recursos naturais estratégicos.

Conforme escreveu Karl Marx sobre o fetiche da mercadoria, o capital tende a transformar tudo em mercadoria. A forma mercadoria se torna tão forte nesse modo de produção que ela se autonomiza e adere às coisas que não são produtos do trabalho humano "[...] coisas que, em si e para si, não são mercadorias, [...] podem ser postas à venda por dinheiro pelos seus possuidores $e$ assim receber, por meio de seu preço, a forma mercadoria” (MARX, 2013, p. 91). O modo de produção capitalista só pode existir como produtor de mercadorias, essa é sua finalidade e, na atualidade, sob a égide do desenvolvimento sustentável, além dos recursos naturais que consideramos como estratégicos, a própria concepção de natureza também tende a se tornar mercadoria (WHITACKER, 2017).

Explicamos o que consideramos como recursos naturais estratégicos para, posteriormente, relacionar a atividade extrativista epidêmica a questão agrária moçambicana. Desde a década de 1950, geógrafos buscam explicar a importância dos recursos naturais, em diferentes perspectivas de análise. Pierre George, dedica um capítulo todo a questão da produção de energia e outro sobre a produção e comercialização das matérias primas indicando, em sua análise, a importância do controle territorial para o acesso, produção e comercialização de determinados produtos, como a energia que, tendencialmente, vai sendo transformada em mercadoria pelos agentes que atuam no controle do modo de produção capitalista (GEORGE, 1980).

Olivier Dolffus, na década de 1970, escrevendo sobre a importância dos recursos naturais e sua valorização, entende que estes dependem, em termos de valorização, de determinado momento histórico.

Os recursos naturais de um determinado espaço só adquirem valor em função de uma sociedade, de uma época e de técnicas de produção determinadas; estão na dependência de uma modalidade de produção e da conjuntura de uma época. A própria noção de recursos naturais parece singularmente estática e seu inventário se afigura algo decisório. A noção de recursos naturais propõe de maneira falsa a questão das relações entre o homem e o 
meio. Como sabemos, não existe recursos em termos absolutos: um recurso só é utilizável com relação a um certo nível de desenvolvimento técnico e à situação geográfica de um espaço (DOLLFUS, 1972, p. 37).

Yves Lacoste, no mesmo período, apresenta a relação entre a expansão do modo de produção capitalista, o controle de recursos naturais e os territórios.

Conflitos entre potências muito grandes desenvolvem-se também em países de grande mercado, situados nos confins das zonas de influência das grandes coalizões: situam-se em territórios onde é possível controlar grandes vias de comunicação mundial, ou recursos cuja extração fornece lucros consideráveis às grandes firmas internacionais. Estas se entregam a lutas ocultas que beneficiam conflitos internos já existentes (ou que os suscitam) para chegar a estabelecer seu monopólio sobre as riquezas que desejam. Estas interações entre lutas internas e conflitos cujos protagonistas são estrangeiros aos países em jogo encontram-se num grande número de países (LACOSTE, 1975, p. 151).

Claude Raffestin descreve a relação entre recursos naturais e os territórios em Por uma Geografia do Poder, publicado originalmente em 1980. Sua afirmação de que o território se forma a partir da apropriação do espaço geográfico - entendido como preexistente ao território, porém, não como receptáculo, o espaço também é produzido por meio de relações sociais de poder. O referido autor faz alusão em relação a transformação de matéria em recursos naturais e, o que nos chama a atenção é a afirmação de que: "A matéria (ou substância), encontrando-se na superfície da terra ou acessivel a partir dela, é assimilável a um "dado”, pois preexiste a toda ação humana [...]." (RAFFESTIN, 1993, p.223, aspas no original). Essa abordagem de Claude Raffestin apresenta significativas contribuições para o entendimento das relações de poder que multinacionais extrativistas implementam no território moçambicano:

Toda relação com a matéria é uma relação de poder que se inscreve no campo político por intermédio do modo de produção [...] O homem não se interessa pela matéria como massa inerte indiferenciada, mas na medida em que ela possui propriedades que correspondem a utilidades. Nessas condições, não é a matéria que é um recurso. Esta, para ser qualificada como tal, só pode ser o resultado de um processo de produção: é preciso um ator (A), uma prática ou, se preferirmos, uma técnica mediatizada pelo trabalho (r), e uma matéria (M). A matéria só se torna recurso ao sair de um processo de produção complexo, que se pode formular de maneira rudimentar: ArM P (conjunto de propriedades ou recursos) (RAFFESTIN, 1993, p. 225, itálicos nossos).

É interessante que para Claude Raffestin não há recursos naturais, mas sim, matérias naturais, tendo em vista que os recursos (P) são resultantes da relação entre ator (A), técnica mediatizada pelo trabalho (r) e matéria (M). Daí que o território constitui um trunfo poderoso para os sujeitos que o controla, uma vez que o território é também fonte de recursos. Essa maneira de conceber os recursos naturais a partir de processos cognitivos e produtivos revela, também, que estes são objetos com potencial funções produtivas, dependendo de suas características. A proposta desenvolvida por Claude Raffestin - ArM-P - explicita o caráter relacional dos mesmos. 
A relação que faz surgir um recurso não é puramente instrumental, mas também política, no sentido de que é um produto coletivo e, portanto, derivado de relações de poder, pois, determinada matéria interessa a diferentes sujeitos econômicos e políticos e o acesso a mesma é modificado de acordo com as necessidades de determinado modo de produção em relação a suas intenções desenvolvimentistas. Portanto, toda relação com a matéria, para transformá-la em recurso natural, é uma relação de poder que se inscreve no campo político por intermédio de sujeitos relacionados a determinado modo de produção, o capitalista, que interfere nos territórios onde megaprojetos multinacionais extrativistas estão localizados. Seguindo essa lógica, um recurso só existe em função de uma prática representada por um agente capaz de mobilizar um conjunto de técnicas e, é por este processo que ocorrem as interferências territoriais.

\begin{abstract}
A tecnicidade pode se definir como o conjunto das relações que o homem, enquanto membro de um grupo, mantém com as matérias às quais pode ter acesso. A tecnicidade, em relação à matéria, é o apêndice da territorialidade, é até mesmo um subconjunto da territorialidade. Da mesma forma que a territorialidade, a tecnicidade de uma sociedade pode ser simétrica ou dissimétrica. Uma tecnicidade simétrica se caracteriza por relações não destrutivas do meio material, enquanto uma tecnicidade dissimétrica será caracterizada por relações destrutivas do meio material (RAFFESTIN, 1993, p. 227).
\end{abstract}

$\mathrm{Na}$ lógica capitalista, escalar e territorialista, é necessário compreender as possíveis propriedades de mercadoria existentes nos territórios e nos recursos naturais e, consideramos que em Karl Marx, os autores anteriormente citados buscaram suas fundamentações, isso porque, a mercadoria é alienante "[...] antes de tudo, um objeto externo que, por meio de suas propriedades, satisfaz necessidades humanas de um tipo qualquer" (MARX, 2013, p. 113) e "Toda coisa útil deve ser considerada sob um duplo ponto de vista: o da qualidade e da quantidade" (MARX, 2013, p. 113). Isso permite considerar que toda mercadoria possui pelo menos duas dimensões, externa e interna. A dimensão externa é aquela como a mercadoria se apresenta no mundo de maneira concreta (quantidade) tendo em vista atender as necessidades humanas, ao que Karl Marx chamou de valor de uso. Por sua vez, a dimensão interna é a que torna todas as mercadorias equivalentes (qualidade) e que geram o valor de troca. Para que as mercadorias possam ser trocadas entre si, é necessário encontrar algo em comum entre elas e reduzir todas elas a esse elemento, o valor (MARX, 2013). Sendo assim subtrai-se o valor de uso e o valor de troca é exaltado.

Multinacionais extrativistas, como a Vale S.A., investem na aceleração pela apropriação, transformação, organização e distribuição dos fatores de produção - recursos naturais - exaltando seu valor de troca. Isso, porque o capitalista ao investir seu dinheiro inicial deseja um retorno acrescido de valor (D'). Esta é a fórmula geral que, de acordo com Marx (2013), permite transformar dinheiro em capital: $\mathrm{D}-\mathrm{M}-\mathrm{D}^{\prime}$. Portanto, seguindo o raciocínio da lógica dinâmica escalar e territorialista do modo de produção capitalista, podemos entender os recursos naturais 
estratégicos como aqueles capazes de produzir, a partir de suas características, energia necessária a circulação de capital produtivo que, como salienta Karl Marx, representa um estágio do processo total do modo de produção capitalista, o qual se revela como unidade de circulação (MARX, 2014).

Sob o capitalismo, consideramos que as ações para a personificação do capital devem ser entendidas sob este aspecto, a interação entre os fixos e fluxos que permitem a circulação, e não restritas somente a produção e consumo. Karl Marx é enfático sobre a importância da circulação. $\mathrm{O}$ mais valor só se realiza quando a forma dinheiro é reincorporada pelo capital. Isso é condição para um novo ciclo, fato que subjaz à assertiva de que, no processo acumulativo, "[...] a circulação não é menos necessária do que a própria produção" (MARX, 2014, p. 206). E isso é tanto mais verdade quanto mais distantes entre si se mostram as conversões D - M. Portanto, a criação de condições físicas fixas é condição de manutenção da fluidez da dinâmica acumulativa. Essa não prescinde do crescimento da demanda efetiva e o alcance de mercados distantes e os meios de transporte são instrumentos logísticos estratégicos. Assinale-se que, como suportes da circulação, essa logística influencia a produção das estruturas espaciais e territoriais, deste, consideramos a importância com que Correa (2006) situa as práticas espaciais em escala e abrangência crescentes no vértice das relações entre a teoria da acumulação e a produção de estruturas espaciais ou da organização territorial.

Karl Marx, no livro II de O Capital, dedica-se a fluidez de capitais. Daí o relevo liminarmente conferido às metamorfoses nos diferentes estágios que integram o circuito que descrevemos a partir da fórmula geral do ciclo produtivo do capital elaborada por Marx (2014): P... $\mathrm{M}-\mathrm{D}^{\prime}-\mathrm{M}^{\prime}$... P. Onde lemos (P...) entendemos produção e interrupção do movimento capital dinheiro, (M - D' - M') significa consumo e retomada do movimento do capital dinheiro possibilitando nova produção (...P) e, nesse aspecto, os recursos naturais possuem contribuição fundamental no processo produtivo, ou seja, a retomada do movimento do capital dinheiro tem que ser acelerada para garantir constantemente a recuperação de mais valor, a transformação de $\mathrm{M}-\mathrm{M}^{\prime}$ (MARX, 2014). Este atributo - necessidade de circulação - alça os recursos naturais energéticos ao ápice dos elementos indispensáveis ao funcionamento do modo de produção capitalista, portanto, estratégicos, pois integram igualmente o que Marx (2014) denomina capital constante circulante, referindo ao valor de "[...] materiais de produção tais como matérias-primas [...]." (MARX, 2014, p. 499). Os recursos naturais são “[...] matérias auxiliares, que ou são consumidos pelos próprios meios de trabalho durante seu funcionamento, tal como o carvão pela máquina a vapor, ou apenas auxiliam no processo, como o gás de iluminação etc. [...].” (MARX, 2014, p. 241), ou seja, energia necessária à produção. Consideramos que quando os agentes personificadores do modo de produção capitalista se referem a recursos naturais entendem estes como indispensáveis para produção, circulação, acumulação e reprodução de capitais. Aí se forma o que consideramos a dialética da 
energia; quanto mais se produz, maior a necessidade da produção de energia, pois a mesma é a matéria das matérias, sem ela, a circulação cessa e, consequentemente, a acumulação também, e essa é a necessidade básica desse modo de produção: “Acumulai, acumulai! Eis Moisés e os profetas!" (MARX, 2013, p. 815).

\section{A QUESTÃO AGRÁRIA E O MEGAPROJETO EXTRATIVISTA DA EMPRESA VALE S.A EM MOATIZE: O EXTRATIVISMO COMO EPIDEMIA}

Disputas envolvendo estados nacionais, que buscam exercer o controle sobre territórios e recursos naturais estratégicos, imprimem um ritmo particular à geopolítica e as relações internacionais, fato esse presente nos dias atuais, conforme declaração do Diretor Geral da Organização das Nações Unidas (ONU):

[...] a exploração de recursos naturais, ou a incorrência sobre eles, pode levar a conflitos violentos. Prevenir, gerir e resolver tais conflitos é um dos grandes desafios de nosso tempo. Estudos da ONU mostram que mais de $40 \%$ dos conflitos internos nos últimos 60 anos foram vinculados a recursos naturais. Desde $1990,75 \%$ das guerras civis na África foram parcialmente financiadas pelas recitas dos recursos naturais. A extração ilegal de minerais, madeira, carvão e vida selvagem alimentou a violência em várias regiões (GUTERRES, ONU, 2018).

Interessante é que, a mesma ONU, que promove discursos em prol de ações humanitárias e do desenvolvimento sustentável, por meio suas agências especializadas em desenvolvimento, no centro do Conselho Econômico e Social (ECOSOC), controladas pelo Grupo BM, foi quem, em Moçambique, em especial, forçou a abertura do país ao mercado econômico por meio de ajustes fiscais fomentados pelo Fundo Monetário Internacional (FMI, 2014) que resultaram na entrada de IED, principalmente a partir da década de 2000, tendo como fim, a implementação do extrativismo epidêmico por meio de megaprojetos.

Quando o controle sobre a exploração de recursos naturais estratégicos como o petróleo, gás natural e carvão se tornam objetivos de multinacionais é porque a essas interessa o uso dos territórios para obter acesso a esses recursos naturais, ou seja, o que está em jogo é a forma de uso dos territórios estabelecidas por meio de relações de poder para gerar o mais valor, ou seja, a transformação dos recursos naturais em mercadorias. Assim, poder e território são conceitos que se relacionam. O território expressa uma relação direta de poder e seu controle permite a configuração e materialização de fixos e fluxos. Nele e através dele conformam-se relações que definem o espaço.

Em Moçambique, país localizado na costa oriental da África Austral, a entrada de megaprojetos mineradores provocou alterações territoriais que impõem ao pesquisador voltado a questão agrária uma profunda reflexão sobre as múltiplas formas de compreender e analisar a 
própria questão agrária, que também assume novas características diante das fases do modo de produção capitalista e suas formas de materialização nos territórios e, ainda, das múltiplas Geografias que permitem estudar esse processo que, em Moçambique é resultante, dentre outros fatores, da desterritorialização de uma parcela significativa de camponeses para a territorialização de megaprojetos extrativistas, esse fato resultou em um profundo processo de conflitualidade, pois a constituição do território extrativista organiza as infraestruturas e os serviços, determinando os tipos de uso dos territórios, expropriando os sujeitos e relações sociais que não são incorporadas ou cooptadas. Atualmente, Moçambique se tornou país hospedeiro de multinacionais extrativistas relacionadas ao setor energético, conforme tabela 1.

Tabela 1 - Multinacionais em Moçambique.

\begin{tabular}{cccc}
\hline Multinacional & $\begin{array}{c}\text { Origem do } \\
\text { Capital }\end{array}$ & Subsidiária & Commodit \\
\hline Anadarko Petroleum & EUA & Anadarko Mozambique & Gás natural \\
Corporation & ITÁLIA & Eni East Africa spa & Petróleo e Gás natural \\
Ente Nazionale Idrocarburi & Sasol Petroleum Temane, & Gás natural \\
Sasol Petroleum International & AFICA DO & Lda & Carvão; logística \\
Vale S.A. & BRASIL & Vale Mozambique & Carvão mineral \\
OP Jindal Group & INDIA & Jindal África & Gás natural e carvão \\
mineral \\
Limited; RINL; NMDC e
\end{tabular}

Fonte: Selemane (2017).

Organização: Guilherme Magon Whitacker (2019).

A conflitualidade em Moçambique é gerada, dentre outros fatores, pela incontestável territorialização de capital estrangeiro que se materializa nos megaprojetos extrativistas. Explicando a conflitualidade, Fernandes (2004) escreveu que esse é um processo constante e promove, concomitantemente, a territorialização, desterritorialização e reterritorialização de diferentes relações sociais. A aparente busca de soluções por parte do governo para reverter o cenário atual da conflitualidade agrária moçambicana - instaurada a mais de uma década (DEUTSCHE WELLE, 2012; ADECRU, 2013; MUTZENBERGER, 2014) - por meio das alterações legislativas, não só tem revelado práticas discursivas ideológicas, como também a emergência de um modus operandi de acordo com a lógica escalar e territorialista do mercado mundializado.

Bernardo Mançano Fernandes contribui sobre o entendimento entre poder e território com o conceito de multidimensionalidade dos territórios (social, cultural, econômica, natural e política), fato que complexifica a leitura sobre sobre os territórios e permite a identificação de movimentos socioterritoriais, pois os mesmos, entendem o território como elemento vital, ou como trunfo, conforme Raffestin (1993). 
Os movimentos socioterritoriais para atingirem seus objetivos constroem espaços políticos, espacializam-se e promovem espacialidades. A construção de um tipo de território significa, quase sempre, a destruição de um outro tipo de território, de modo que a maior parte dos movimentos socioterritoriais forma-se a partir dos processos de territorialização e desterritorialização. (FERNANDES, 2005, p. 31).

Assim, compreender o Estado moçambicano, a Vale Moçambique, os camponeses e camponesas desterritorializados, as associações da sociedade civil, que de uma forma ou outra atuam em favor das famílias camponesas, como movimentos socioterritoriais é imprescindível a nossa pesquisa.

O espaço, o território, o lugar, as relações sociais, as escalas das ações nos ajudam a compreender os tipos de movimentos socioespacial ou socioterritorial e seus processos geográficos (isolados, territorializados ou espacializados). Esses movimentos são tanto instituições formais, quanto não formais, políticas no sentido lato, por sua materialidade, ação, estabelecimento e dinâmica, quanto são igualmente instituições formais como os sindicatos, as empresas, os estados, as igrejas e as organizações não governamentais (ONGs). Nesse sentido, é preciso diferenciar entre os movimentos socioespaciais e os movimentos socioterritoriais. Os movimentos socioterritoriais têm o território não só como trunfo, mas este é essencial para sua existência. Os movimentos camponeses, os indígenas, as empresas, os sindicatos e os estados podem se constituir em movimentos socioterritoriais e socioespaciais. Porque criam relações sociais para tratarem diretamente de seus interesses e assim produzem seus próprios espaços e seus territórios. (FERNANDES, 2005, p. 31, itálicos nossos).

Do processo de territorialização da Vale S.A. em Moatize e desterritorialização camponesa resultam impactos e, apesar dos impactos socioterritoriais negativos detectados por pesquisadores moçambicanos (MOSCA, 2011, 2014; SELEMANE, 2013; CASTEL-BRANCO, 2015; MATOS, 2016) e denunciado por entidades públicas (CIP, 2014; IESE, 2013), o megaprojeto da Vale Moçambique é visto pelo governo nacional como uma forma de promoção de IED, o que garantiria o impacto positivo do mesmo, e, com ele, a garantia de transferência de tecnologias para o país em vista da dinamização territorial indo ao encontro daquilo que Giovanni Arrighi escreveu sobre a lógica de domínio capitalista sobre o território (ARRIGHI, 2014). O governo moçambicano atua de acordo com os ditames do novo imperialismo (HARVEY, 2012), ignorando as situações de risco presentes na instalação e operacionalização de megaprojetos e objetivando a produção de lucro por meio da extração de commodities minerais, no caso o carvão. A não observação do fator de risco para as comunidades camponesas desterritorializadas representa uma ação de poder da Vale Moçambique sobre o governo local, pois a mesma demonstra a exclusiva intervenção da multinacional em detrimento da população local tendo em vistas exclusivamente a obtenção de lucros. De acordo com Flyvbjerg (2013) a não observação dos fatores de risco representam:

[...] some problems that are not taken into account during project preparation tend to surface during construction and operations; and such problems often destabilise habitats, communities and megaprojects themselves, if not dealt with carefully. Moreover, positive regional development effects, typically much touted by project promoters to gain political 
acceptance for their projects, repeatedly turn out to be non-measurable, insignificant or even negative (FLYVBJERG, 2013, p. 4).

A abordagem de Flyvbjerg (2013) agrega à concepção de megaprojetos sua face não visibilizada no que refere a grupos sociais, pressupostos de ordem natural e mobilizações políticas que são invisibilizadas por imperativos financeiros. Neste caso, relações de poder - entre a sociedade e a natureza; populações locais versus investidores; países hospedeiros versus países de origem dos investimentos - podem estar em jogo, pois na sua atividade, eles empregam equipamentos pesados e tecnologias sofisticadas e requerem fluxos de coordenação com o capital financeiro internacional (GELLERT; LYNCH, 2003). Fato este que retira dos países hospedeiros e das comunidades afetadas a possibilidade de diálogo com as multinacionais. Dessa situação, Moatize apresenta uma série de impactos socioterritoriais positivos e negativos. Mosca (2011) demonstra esses impactos:

A actividade mineira fez crescer a demanda interna e consequente oferta de bens e serviços de primeira ordem (efeito imediato). Alguns têm, necessariamente, que ser fornecidos localmente, como são os casos da hotelaria, restauração, arrendamento imobiliário e transportes de curta distância, maioritariamente através de empresas com sede na zona. Outras actividades fazem incrementar a oferta de serviços de empresas nacionais e ou estrangeiras como o fornecimento de energia, transportes de longa distância e serviços bancários. As demandas de primeira ordem são satisfeitas pela oferta de novos empreendimentos ou a extensão de actividades para as cidades de Tete e Moatize, como são os transportes aéreos a partir de várias capitais provinciais e da África do Sul, a energia de Cahora Bassa e estações de serviços de assistência técnica aos transportes, postos de abastecimento de combustíveis, agências bancárias e outros serviços (MOSCA, 2011, p. 21).

A exploração mineira implica a movimentação de populações. O processo tem sido aparentemente dirigido pelos organismos do governo local, que possui uma comissão chefiada pela Secretária Permanente do Governo provincial, que reúne várias direcções provinciais, administradores distritais e as empresas mineiras. Na realidade quem executa o reassentamento são as empresas, mesmo que a decisão dos locais do reassentamento seja do Governo Provincial, mediante apresentação de várias propostas alternativas indicadas pelas empresas. Por exemplo, uma fonte da Vale refere que a empresa tinha apresentado ao Governo Provincial 10 opções de locais para os quais as pessoas afectadas pelo mega projecto de Moatize deveriam ser transferidas. Foi dessas 10 alternativas que foi escolhida a localidade de Cateme, que dista 40 quilómetros da Cidade de Tete. Nem as populações nem os seus representantes participam na comissão do Governo, que se assume como representante dos interesses do povo (MOSCA, 2011, p. 39).

Além destes, que contém relação exclusiva com as comunidades diretamente impactadas, durante a realização de uma das entrevistas com representantes da sociedade civil nos foram revelados outros aspectos referentes ao Distrito de Tete:

Podemos falar que em Tete outros aspectos impactaram negativamente... desde 2009 temos informações que estão a revelar vários problemas... a cidade ficou muito lotada e com o fim das obras de instalação muitos trabalhadores não conseguiram voltar para seus lugares de origem e acabaram ficando em Tete, os que conseguiram algum tipo de emprego foram morar nas periferias, em Bagamoyo, por exemplo, que está com problemas sérios... em Tete o aumento da criminalidade, prostituição e desemprego formal causados após a instalação 
da mina da Vale Moçambique é um problema até hoje (Depoimento, representante da sociedade civil, trabalho de campo, Maputo, julho de 2018).

Conceitualmente e economicamente os megaprojetos são entendidos, principalmente a partir do total de capital investido. Para Castel-Branco (2014); Fiori e Kovaka (2005); Zhai (2009) e Flyvbjerg (2013), por exemplo, esse valor está na ordem de US\$1.000.000,00. Com base nesses autores e para além da definição com base nos investimentos, os megaprojetos podem ser entendidos a partir de características geográficas, tais como, a representação material (territorialidade) da reprodução do modo de produção capitalista na contemporaneidade, a magnitude e operacionalidade (escala de comando e escala de ação), envolvendo um conjunto de interesses, principalmente econômicos, políticos, e técnicos, que permitem a mobilidade espacial de capitais e a fixação territorial dos mesmos (fixos e fluxos) alternando os usos dos territórios por meio da implementação de um poderoso artefato técnico. Essas são, portanto, as características do megaprojeto de carvão Moatize que nos permite qualificá-lo como atividade extrativista epidêmica.

Essas características, devido à necessidade de garantir a exequibilidade e concretização de seus objetivos, transcendem o poder do Estado hospedeiro, no caso Moçambique, pois estão em jogo grandes interesses econômicos e políticos da Vale S.A., o que determina o poder desta e subordina a ação política do Estado. Portanto, o crescimento e a ação de megaprojetos fazem-se acompanhar de um conjunto de regulamentos e de um corpus de normas que viabilizam suas ações e pretensões, daí a necessidade da normatização dos territórios por parte do governo tendo em vistas a expropriação da terra que antes pertencia ao camponês, processo esse que constitui a base da acumulação de capitais desde a acumulação primitiva. Na atualidade, considerando que a acumulação primitiva segue seu curso com base na expropriação de terras, "E a história da expropriação está gravada nos anais da humanidade com traços de sangue e fogo" (MARX 2013, p. 787), David Harvey, examinando atentamente esse processo, escreveu sobre a acumulação por espoliação e identifica suas características, aqui destacamos o processo de mercadificação de terras com a desterritorialização camponesa e todos os processos resultantes desse ato, tal como a supressão de formas tradicionais de produção. A acumulação por espoliação está relacionada com o poder desempenhado pela Vale Moçambique, o processo que dá início a acumulação primitiva, conforme escreveu Marx (2013), a expropriação de terras, está presente em Moçambique. Assim, a acumulação por espoliação segue seu curso tendo o Estado presente como "[...] um comitê para gerir os negócios comuns de toda classe burguesa". (MARX; ENGELS, p. 43, 2017), essa afirmação sobre o papel do Estado contribui com aquilo que Pierre Dardot e Christian Laval escreveram sobre a governança empresarial. 
A "governança" foi descrita muitas vezes como um novo modo de exercício do poder que implica instituições políticas e jurídicas internacionais e nacionais, associações, igrejas, empresas, think tanks, universidades, etc. Sem entrar aqui na natureza do novo poder mundial, é forçoso constatar que a nova norma concorrencial implicou o desenvolvimento crescente de formas múltiplas de concessão de autoridade às empresas privadas, a ponto de podermos falar, em muitos domínios, de uma coprodução público-privada das normas internacionais (DARDOT; LAVAL, 2016, p. 277, aspas e itálico no original)

Portanto, o desenvolvimento do modo de produção capitalista dependeu, e continua a depender, da maneira vital do agir do Estado que vem mantendo as lógicas territorial e capitalista de poder sempre interligadas, ainda que não necessariamente convergentes. Todos esses fatos, fazem com que a questão agrária moçambicana adquira distintos contornos e intensifique a conflitualidade, pois a acumulação por espoliação, articulada e executada pela Vale Moçambique em parceria com o governo, expropriou de camponeses de Moatize - foram reassentadas, a partir de 2009, 1.313 famílias, em um total 5.423 pessoas - não somente a terra, a machamba ${ }^{5}$, foi muito mais do que isso.

\begin{abstract}
Aqui não temos mais nada, estamos a ver tudo acabar... antes tinha a machamba, o rio para pesca, lá, nós fazíamos tijolos pra vender quando tinha algum problema com a plantação... aqui o Senhor pode ver, como plantar alguma coisa aqui? O chão é de pedra, o rio está a mais de 10 quilômetros... não temos nada. Aqui, o que fazemos é acordar, sentar e esperar morrer (Depoimento, reassentamento 25 de setembro, trabalho de campo, Moatize, agosto de 2018).
\end{abstract}

Nesse contexto, a Vale S.A. e o Estado moçambicano são aqui considerados como sujeitos na produção dos impactos socioterritoriais em Moatize, ou seja, como movimentos socioterritoriais com poderes geopolíticos, devido ao poder de influência da multinacional mineradora, hoje, não só as relações entre os Estados podem ser consideradas objeto de análise da geopolítica. Portanto, trabalhamos aqui com a geopolítica dos recursos naturais energéticos, entendendo que a disputa global pelos mesmos é um dos elementos mais marcantes da dinâmica do modo de produção capitalista na contemporaneidade e de sua lógica de acumulação. Conforme escreveu Neil Smith:

Debaixo da ordenação do processo de acumulação, o capitalismo, como um modelo de produção deve-se expandir continuamente para sobreviver. [...] Para este fim, o capital se volta para a superfície do solo em busca de recursos naturais; a natureza torna-se um meio universal de produção, de modo que ela não somente provê o sujeito, o objeto e os instrumentos de produção, mas ela é em sua totalidade um acessório para o processo de produção (SMITH, 1988, p. 88).

Para Monica Bruckman:

Una de las características más marcantes de nuestro tiempo es la creciente importancia de los recursos naturales en función de su utilización, a partir de los avances científicos y tecnológicos producto de un conocimiento cada vez más profundo de la materia, la naturaleza y la vida. Al mismo tiempo, estos avances científicos convierten a la naturaleza

\footnotetext{
${ }^{5}$ Palavra moçambicana, área utilizada para plantações.
} 
en un campo de su propia aplicación. De esta forma, la relación entre recursos naturales y desarrollo científico adquiere una articulación cada vez mayor[...] El sistema mundial basado en la división internacional del trabajo entre las zonas industriales y manufactureras y los países productores de materias primas, minerales estratégicos y productos agrícolas, consolidó el poder hegemónico de los países centrales y su dominio en relación a las zonas periféricas o dependientes y los espacios económicos que ocuparon una posición de semiperiferia. Así, la elaboración industrial de las materias primas que exportaban los países periféricos tendió a ser la menor posible, consolidando y ampliando la dependencia económica, pero también la dependencia científica y tecnológica de estas regiones (BRUCKMAN, 2011, p. 6).

A partir dessas observações, consideramos que a questão agrária não é somente um problema de renda da terra derivada da posse; fazer uma análise somente a partir desse aspecto é uma visão redutiva, a questão agrária é, também, geopolítica, envolvendo agentes nacionais e internacionais que materializam suas práticas acumulativas em determinados territórios.

\section{CONSIDERAÇÕES FINAIS}

A disputa global por recursos minerais, recursos energéticos, gestão da biodiversidade, da água e dos ecossistemas frente aos avanços científicos se desdobra em múltiplas dimensões políticas, econômicas e militares. Sem o desenvolvimento de um pensamento estratégico que se afirme no princípio da soberania e em uma visão de futuro a longo prazo, os países subdesenvolvidos, exportadores de commodities, tem menos condições de fazer frente as enormes pressões geradas por esta situação de disputa, onde está em jogo, em última instancia, a capacidade de reorganização de projetos hegemônicos e a emergência de projetos contra hegemônicos. É evidente que este conflito de interesse tem como pano de fundo visões societárias e projetos civilizatórios em choque e, esses aspectos, podem ser estudados pela geopolítica dos recursos naturais.

O que nos importou aqui foi destacar o critério geopolítico altamente dinâmico com que devemos dedicar nossas atenções aos recursos naturais estratégicos, assim como as profundas mudanças que sobre eles desatam as necessidades econômicas e políticas, tanto das comunidades aonde esses recursos estão, assim como de todas aquelas sociedades cujos territórios dependem de energia, bem como das forças políticas e econômicas externas que atuam na produção de commodities. O conceito de recurso natural estratégico é muito mais amplo e variável no tempo e no espaço do que normalmente imaginamos. 


\section{REFERÊNCIAS}

ADECRU. Famílias atingidas dão ultimato a Vale e ameaçam endurecer a luta. Disponível em: https://adecru.wordpress.com/2013/04/22/familias-atingidas-dao-ultimato-a-vale. Acesso em: 13 dez. 2018.

AGNEW, J. Geopolitics. Re-visioning world politics. London: Taylor e Francis Group, 2014. $168 \mathrm{p}$.

AGNEW, J. The origins of critical geopolitics. In: DODDS, K.; KUUS, M.; SHARP, J. The Ashgate Research Companion to Critical Geopolitics. London, 2016.

ANDERSON, E.; ANDERSON, L. Strategic Minerals: Resource Geopolitics and Global GeoEconomics. New Jersey: Wiley, 2018. 180p.

ARRIGHI, G. El largo siglo XX. Dinero y poder en los Orígenes de nuestra época. 2. ed. Madrid: Akal, 2014. 452p.

BAVINCK, M.; PELLEGRINI, L.; MOSTERT, E. Conflicts over Natural Resources in the Global South - Conceptual Approaches. London: Taylor \& Francis Group, 2014. 224p.

BRUCKMAN, M. Recursos naturales y la geopolítica de la integración sudamericana. https://cronicon.net/paginas/Documentos/Libro-Bruckmann.pdf Creative Commons, 2011. 88p.

CASTEL-BRANCO, C. N. Os megaprojetos em Moçambique: que contributo para a economia nacional?. In: FÓRUM DA SOCIEDADE CIVIL SOBRE INDÚSTRIA EXTRATIVA, 1., Maputo. Anais... Maputo. 2009.

CASTEL-BRANCO, C. N. Economia extractiva e desafios de industrialização em Moçambique. Maputo, Cadernos IESE, n. 1. 2015.

CIP. Centro de Integridade Pública. Compreendendo os novos termos legais para Actividade Mineira. Maputo, 2014. Disponível em: https://cipmoz.org/category/industria-extractiva/page/4/ Acesso em: 25 ago. 2018.

CORRÊA, R. L. Espaço: um conceito chave da Geografia. In: CASTRO, I. E.; GOMES, P. C. C.; CORRÊA, R. L. Geografia: conceitos e temas. Rio de Janeiro: Bertrand Brasil, 2006.

DALBY, S. Critical geopolitics: discourse, difference, and dissent. Environment and Planning: Socioty and Space, 1991. p. 203-261. Disponível em: https://www.researchgate.net/publication/248881184_Critical_Geopolitics_Discourse_Difference_a nd_Dissent. Acesso em: 26 jul. 2018.

DARDOT, P.; LAVAL, C. A nova razão do mundo. Ensaio sobre a sociedade neoliberal. 1. ed. São Paulo: Boitempo, 2016. 416p.

DEUTSCHE WELLE. Interesses obscuros causam conflitos de terras em Moçambique, diz Igreja Católica. 2012. Disponível em: https://www.dw.com/pt-002/interesses-obscuros-causamconflitos-de-terras-em-mo\%C3\%A7ambique-diz-igreja-cat\%C3\%B3lica/a-38684159. Acesso em: 21 out. 2018. 
DODDS, K.; KUUS, M.; SHARP, J. The Ashgate Research Companion to Critical Geopolitics. Ashgate London: Ashgate, 2016. 588p.

DOLLFUS, O. O espaço geográfico. São Paulo: Difusão europeia do livro, 1972. 128p.

FERNANDES, B. M. Questão agrária: conflitualidade e desenvolvimento territorial. In: BUAINAIN, A. M. (Org.). Luta pela terra, reforma agrária e gestão de conflitos no Brasil. Campinas: Unicamp. 2008.

FERNANDES, B. M. Sobre a tipologia dos territórios. In: SAQUET, M. A.; SPOSITO, E. S. Territórios e territorialidades: teorias, processos e conflitos. Expressão popular: São Paulo, 2009.

FIORI, C.; KOVAKA, M. Defining Megaprojects: Learning from Construction at the Edge of Experience. In: CIVIL ENG CONST RESEARCH CONGRESS, 1., 2005. San Diego. Proceedings... San Diego. 2005.

FLYVBERJG, B. Megaprojects and Risk: An Anatomy of Ambition. Cambridge: Cambridge University Press, 2013. 215p.

FUNDO MONETÁRIO INTERNACIONAL (FMI). Departamento de África. Moçambique em ascensão. Construir um novo dia. Washington, 2014.

GELLERT, P.; LYNCH, B. Mega-projects as displacements. Blackwell Publishing Ltd. UNESCO, 2003.

GEORGE, P. Geografia econômica. 3. ed. São Paulo: DIFEL, 1980.

HAGLUNG, D. The New Geopolitics of Minerals: Canada and International Resource Trade. University of British Columbia: Univ. of British Columbia, 1999. 273p.

HARVEY, D. O novo imperialismo. 6. ed. São Paulo: Loyola, 2012. 208p.

HARVEY, D. O enigma do capital: e as crises do capitalismo. São Paulo: Boitempo, 2011. 240p.

HARVEY, D. A produção capitalista do espaço. 1. ed. São Paulo: Annablume, 2005. 252p.

HENDRIX, C.; NOLAND, M. Confronting the curse. The economics and geopolitics of natural resource governance. Peterson institute for internacional economics. New York: Columbia University Press, 2014. 188p.

IESE. Instituto de Estudos Sociais e Econômicos. Desafios para Moçambique. Vítimas da riqueza? A reprodução da pobreza em zonas de mineração. Maputo: IESE, 2018.

KLARE, M. Rising powers, shrinking planet. The new geopolitics of energy. New York: Metropolitan Books, 2018. 352p.

KLARE, M. The race for what's left: The global scramble for the world's last resources. New York: Picador, 2012. 320p.

KLARE, M. Blood and Oil: The Dangers and Consequences of America's Growing Dependency on Imported Petroleum. New York: Penguin Books. 288p. 
KLARE, M. Resource Wars - The new landscape of global conflict. New York: Metropolitan books. 2001. 304p.

LACOSTE, Y. A geografia: isso serve, em primeiro lugar, para fazer a guerra. Campinas: Papirus, 2012. 240p.

LACOSTE, Y. Geografia do subdesenvolvimento. 4. ed. São Paulo: DIFEL, 1975. 264p.

LE BILLON, P. The geopolítics of resource wars. Resource dependence, governance and violence. Frank Cass, 2005. 284p.

LE BILLON, P. The Geopolitical economy of resource wars. Geopolitics Published online, v. 9, n. 1, p. 1-28, 2010.

LEE, B. The Geopolitics of the Modern Resource Boom. From issue: natural resource extraction in latin américa. Winter, 2013. Disponível em: https://www.americasquarterly.org/content/geopolitics-modern-resource-boom. Acesso em: 05 out. 2018.

MARX, K. O Capital: crítica da economia política. Livro I. O processo de produção do capital. Boitempo: São Paulo, 2013. 1783p.

MARX, K. O Capital: crítica da economia política. Livro II. O processo de circulação do capital. Boitempo: São Paulo, 2014. 600p.

MARX, K.; ENGELS, F. Manifesto comunista. São Paulo: Boitempo, 2007. 254p.

MATOS, E. A. Desterritorialização e reterritorialização das comunidades atingidas pela exploração do carvão mineral em Moatize, Moçambique. 2016. 295 f. Tese (Doutorado em Geografia) - Instituto de Geociências, Universidade Federal do Rio Grande do Sul, Porto Alegre, 2016.

MILANEZ, B.; SANTOS, R. S. P. Neodesenvolvimentismo e neoextrativismo: duas faces da mesma moeda? In: ENCONTRO ANUAL DA ANPOCS, 37., Águas de Lindóia. Anais... Águas de Lindóia: ANPOCS, 2013. p. 1-30.

MOSCA, J. Mega-projectos no meio rural, desenvolvimento do território e pobreza: o caso de Tete. Maputo: IESE, 2012.

MOSCA, J.; SELEMANE, T. El dorado Tete: os mega-projectos de mineração. Maputo: CIP, 2011.

MUTZENBERGER, R. Projetos sociais em Moçambique. Uma agenda de pesquisa. Civitas, Porto Alegre, v. 14. n. 1. p. 137-153, 2014.

NEVINS, J. Resource conflicts in a new world order. Geopolitics, v. 1, n. 1, p. 255-263, 2010.

OLAYELE, F. The Geopolitics of Oil and Gas. International Association for Energy Economics, p. 29-31, 2014.

OVERLAND, I. Future Petroleum Geopolitics: Consequences of Climate Policy and Unconventional Oil and Gas. Energy vs. Development, p. 1-29, 2015 
PEET, R. International Capitalism and Industrial Restructuring: a critical analysis. Allen \& Unwin. 1987. 315p.

PEET, R. Radical Geography: Alternative Viewpoints on Contemporary Social Issues. Maroufa Press, 1977. 387p.

PORTO-GONÇALVES, C. W. A natureza da globalização e a globalização da natureza. 6. ed. São Paulo: civilização brasileira, 2015. 462p.

RAFESTTIN, C. Por uma geografia do poder. 1. ed. São Paulo: Ática, 1993. 269p.

RIBEIRO, W. C. A ordem ambiental internacional. São Paulo: Contexto, 2001. 180p.

RIBEIRO, W. C. Geografia política e gestão internacional dos recursos naturais. Estudos Avançados, São Paulo, v. 24, n. 68, p. 69-80, 2010.

SELEMANE, T. Alguns desafios da indústria extractiva em Moçambique. Maputo: CIP, 2009. $6 \mathrm{p}$.

SMITH, N. Desenvolvimento desigual. Natureza, capital e a produção do espaço. Rio de Janeiro: Bertrand Brasil, 1998. 250p.

TUATHAIL, G. Ó. Critical geopolitics. The politics of writing global space. Minnesota: Taylor and Francis e-library, 2005. 328p.

WELZER, H. Guerras climáticas. Por qué mataremos (y nos matarán) en el siglo XXI. Madrid: Kartz Editores, 2010. 346p.

WHITACKER, G. M. Desenvolvimento sustentável: decifra-me ou te devoro. Análise sobre o desenvolvimento sustentável no modo de produção capitalista. 2017. 332 f. Tese. (Doutorado em Geografia) - Departamento de Geografia, Universidade Estadual Paulista “ Júlio de Mesquita Filho", Presidente Prudente, 2018.

ZHAI, L.; XIN, Y.; CHENG, C. Understanding the value of project management from a stakeholder's perspective. Project Management Journal, v. 40, n.1, p. 99-109, 2009.

ZHOURI, A. Produção de conhecimento em um campo minado. In: ZHOURI, A. (Org.). Mineração, violências e resistências. Um campo aberto à produção de conhecimento no brasil. Marabá: iGuanna, 2018. p. 1-27. 